\title{
Talk Matters: The Role of Pivot in the Distribution of Literacy Knowledge Among Novice Writers
}

\author{
JOANNE LARSON \\ University of Rochester
}

\begin{abstract}
Data drawn from an ethnographic study of kindergarten journal writing activity suggest that literacy knowledge is distributed socially through shifts in participant roles, or footings, within the participation framework of the activity. Discourse analysis of moment-to-moment talk and interaction reveals that activity participants assume a variety of participant roles available in the participation framework. By assuming these roles, literacy knowledge is distributed from restricted teacherstudent dyads to other student overhearers. In this way, the participation framework highlights the ways in which participants in writing activity gain access to the social distribution of literacy knowledge that may otherwise be limited by restricting talk to dyadic interaction. Furthermore, the role of the participation framework as a mediating tool in purposeful writing activity is emphasized as a key factor in the distribution of literacy knowledge.
\end{abstract}

The world of kindergarten is colorful, energetic, and full of exuberance. Children come together to learn how to share, to take turns, to play, draw, paint, run, and to laugh out loud. Somewhere in this whirlwind of contagious excitement, students learn that those black lines on the pages of books have meaning and, best of all, that they can share that meaning with others. An explosion of letter writing, drawing, and labeling occurs as they try out this new communicative tool. The ethnographic study described in this article examines this dynamic social process in one kindergarten classroom and follows a group of 5-year-olds as they explore the world of print.

The primary goal of this study is to examine how literacy knowledge is distributed and appropriated through talk among novice writers in kindergarten journal-writing activity. In particular, I observed writing in interactive context in order to describe what particular conditions and forms of interaction constitute

I thank Kris Gutierrez and Elinor Ochs for their contribution to the formation of the theoretical and analytic frameworks used in this study. In addition, I thank the anonymous reviewers of this article. Their insightful comments and valuable suggestions for revision significantly enhanced both the clarity of the article and my understanding of the data.

Correspondence and requests for reprints should be sent to Joanne Larson, 1-160E Dewey Hall, University of Rochester, Wamer Graduate School of Education and Human Development, Rochester, NY 14627. 
the learning context within which the social distribution and appropriation of literacy knowledge occurs. Specifically, this study asks how this social distribution of knowledge occurs within the participation framework of a journal-writing activity in which the students dictate their stories to the teacher. A participation framework is defined as a structure of activity roles that organizes and is organized by talk and interaction (Goffman, 1981). Through analysis of ethnographic data and microanalysis of the talk and interaction surrounding writing activity, this study examines how context, interaction, and discourse reflect and create the social processes involved in learning to write.

This distribution process is examined through an analysis of the changing roles students assume over time within the participation framework. The examination of participant roles is made possible through microanalysis of the connection between knowledge distribution and shifts in footing (Goffman, 1981), or participant roles, within the participation framework of the activity. Five principal roles have been identified in the participation framework: (a) teacher-scribe, (b) primary author, (c) peripheral respondent, (d) overhearer, and (e) pivot. I argue that it is through these changing roles that students create a contagious process of knowledge distribution that results in socially shared and distributed learning. This article focuses specifically on the role of pivot as a key participant role in the social distribution of literacy knowledge. This distribution process is examined using sociocultural theories of learning and development that explore context as a "socially constituted, interactively sustained, time-bound phenomenon" (C. Goodwin \& Duranti, 1992).

Although there is a body of research from various theoretical perspectives that has documented the role that talk plays in the learning process, it has not examined this role on a microlevel to document how the structure of talk in activity constitutes the context for learning. Using cultural-historical and sociocultural theories of learning and theories of language socialization, evidence of talk and interaction in writing activity is presented as constituting a learning context that allows for the distribution and appropriation of literacy knowledge among the participants. From a sociocultural perspective, learning occurs through participation in culturally organized activity. All participants are transformed by their participation in activity on what Rogoff $(1992,1994)$ termed the three planes of apprenticeship. In other words, learning occurs simultaneously on a personal or individual plane, on an interpersonal or group plane, and on a community or social plane. How participation changes over time, then, becomes evidence of learning on both a personal and interpersonal level and implies that learning contexts allow for flexible participation in activity. This participation model of learning contrasts with the more traditional internalization models that view learning as the transmission of a set body of knowledge and assume a separation of the individual from other participants in activity. Theories of language socialization contribute to a participation model of learning by articulating the ways in which, through participation in language activities, children are socialized to use 
language or, in other words, to gain communicative competence (Ochs, 1988; Ochs \& Schicffclin, 1983; Schicffclin \& Ochs, 1986). In this way, lcarning to write becomes a socialization process in which culture and cognition are mutually constituted and mediated through language.

Theories of language socialization contribute to the understanding of how the relation of language to writing activity is linked to changing roles or stances that participants assume during writing activity (Ochs, 1992). By understanding these shifting roles, researchers can observe how the production and comprehension of text is interactionally negotiated and how, in particular, language contributes to learning as a socially mediated process (Ochs, 1988). From this perspective, becoming a competent member of a community of learners, such as a community of writers, has to do with the ways in which children are socialized to use certain forms and conventions of writing that are valued as indicators of competence by the teacher and the larger social context. This study draws from theories of language socialization to describe the socially shared process of learning to write as "writing socialization"; that is, children are socialized to become competent ${ }^{1}$ writers through active participation in meaningful literacy activity. Following Ochs's (1988) argument that children are socialized through language and to use language, I argue for an elaboration of this notion that holds that children are socialized through writing and to use writing in particular ways by participating in language activity. It is through participation in language activities at home and in school that children are socialized to become competent writers in their community (Heath, 1983).

Research informed by earlier views of learning, however, tends to focus on talk as evidence of individual cognitive development and to define learning to write as a reciprocal process of assimilation and accommodation (DudleyMarling \& Searle, 1991; Ferreiro, 1978). Bereiter and Scardamalia (1982) concluded that children must adapt oral language skills to written conventions. The connection of talk and writing, then, is one of transition to more formal, independently produced written language. The role talk and associated interaction play in the process of learning to write is not acknowledged as significantly contributing to learning in the information processing model of learning used in these studies. Talk is discussed only in terms of its differentiation from writing and how children must learn to transform speech into written form using the conventions of writing (Nichols et al., 1989). Peers and adults present in activity are relegated to the status of empathetic audience whose primary role is to serve as a reflecting mirror for the writer (Arnold, 1991). The role that activity participants play in the community construction of text is not examined in these theoretical paradigms.

More recent research on the role of talk in writing activity informed by sociocultural theories of learning examines learning to write as a complex social process through which children construct a social self in relation to others and examines how this process is mediated through talk in writing activity (Dyson, $1987,1989,1992,1993 \mathrm{a}, 1993 \mathrm{~b})$. Children's composing is understood to con- 
nect their social worlds with the worlds of the other activity participants and the resulting texts are given meaning through talk (Dyson, 1993a). In this view, writing is a way of speaking and listening to others and grows out of drawing, gesture, and play (Gundlach, 1992). Children's writing, then, cannot be understood apart from the talk and interaction during joint participation in writing activity (Dyson, 1993b). Texts are embedded in social dialogue and contain the multiple voices of the child's sociocultural past, present, and future (Bakhtin, 1981: Ochs, Taylor, Rudolph, \& Smith, 1992). This study builds on this current body of sociocultural research by examining how the talk surrounding writing activity constitutes the means through which learning to write is a socially shared and distributed process. Specifically, I argue that the multiple and overlapping texts activity participants (both students and teacher) bring to joint writing activity create the intertextual space for social distribution of literacy knowledge to occur. The resulting texts, then, are interactionally negotiated, acknowledged, and gain social significance (Bloome, 1991) through joint participation in activity. In this way, this study contributes to the understanding of the complex dynamic between talk and learning to write by delineating how this relationship is constituted linguistically in the participation framework.

Observing the organization of talk in everyday literacy activities allows researchers to analyze how contextually situated talk influences learning in general, and learning to write, in particular. Analysis of face-to-face interaction in purposeful writing activity, therefore, provides an opportunity to study language, culture, and social organization in context (M. Goodwin, 1990). In the following section, the ethnographic methodology that was used in this study is presented as a means to examine how talk constitutes the primary activity of young children learning to write and how this talk influences and is influenced by the context within which writing activity occurs.

\section{STUDY DESIGN AND ANALYTIC FRAMEWORK}

Data were collected on a weekly basis for the academic year using ethnographic methods later described. Journal-writing activity was videotaped to visually and auditorily document talk and interaction in activity. Field notes were collected during weekly participant observation of journal-writing activity in order to present a rich picture of the whole context, particularly what occurred outside of the camera. Teacher and student interviews were conducted and transcribed to give voice to the participant's perspective on learning to write. Students' written journal entries were collected to compare what was said with what was written on paper. Each videotape was viewed and a tape summary made. Key segments were identified during this analytic process and were subsequently transcribed. These transcribed segments were used for detailed discourse analysis of face-toface interaction and serve as the primary data base. Detailed analysis of the participation framework is based on these selected portions of the basic transcript 
in order to present specific data as evidence of socially shared learning (Ochs, 1979). A participation framework was devcloped for each identified segment and was coded based on the five emerging participant roles of teacher-scribe, primary author, overhearer, peripheral respondent, and pivot.

As mentioned, transcriptions of videotaped observations serve as the primary data base for analysis of classroom discourse. Transcription conventions derived from Atkinson and Heritage (1984) were used in transforming these data into text. Transcription of discourse, or the process of inscribing social action (Duranti, in press), enables the microanalysis of how language use among activity participants influences the writing process. Nonvocal, vocal, gestural, and timing features were all transcribed and treated as additional evidence of children's developing linguistic competence (Ochs, 1979). In this way, a record of the interaction between participants in writing activity is created. It is important to remember, however, that this inscription of talk and interaction is an abstraction of complex phenomena that represents what is of theoretical and analytical focus in this study (Duranti, in press; Ochs, 1979).

In this study, the talk and interaction surrounding writing activity were examined through analysis of the participation framework (Goffman, 1981; M. Goodwin, 1990; Philips, 1983). By delineating the participation framework, a structural basis for analyzing changes in participation status is created (Goffman, 1974, 1981). In classroom contexts where there are multiple participants in activity, not all participants will have equal access to the accompanying talk. This variation in participant roles necessarily establishes boundaries or rules for participation that students and teacher negotiate over time. $\Lambda$ s a result, there are multiple and overlapping frames of participation (Goffman, 1974) to accommodate the varying roles developed in the classroom. Consequently, it becomes important to examine the processes involved in negotiating these participation frameworks in order to understand how these negotiations contribute to socially shared learning.

Specifically, I adapt Goffman's notion of footing, or participant role, to look at how, in particular, the participation framework structures knowledge distribution in writing activity. Goffman (1981) identified one such role as a pivot, for example, and describes this position as occupied by an individual who participates in two conversations, alternating, or pivoting, between the two. As a result of the analysis presented in this article, the definition of pivot is redefined as an "open" position in which an activity participant takes information or knowledge from one dyadic interaction and carries it into the creation of another dyad, thereby facilitating the knowledge circulation process and expanding the participation framework. In this study, I expand the notion of participation roles by applying the theory to classroom interaction in order to determine how the participation structure organizes and is organized by the social processes inherent in the transformation of knowledge as it is appropriated and distributed in context. 


\section{THE SCHOOL COMMUNITY}

Kindersley 2 is one of seven elementary schools in a small community surrounded by the city of Los Angeles. The school is located toward the eastern end of the community and is bordered by neatly kept, middle-class, single-family homes on the west and south sides, one of the local film studio facilities and apartment buildings on the east side and City Unified School District offices on the north. This community is traditionally viewed as a middle-class enclave, but there are many pockets of low-income multifamily homes that are served by the school. The school was recognized by the state of California in 1993 as a California Distinguished School. A banner marking this honor is proudly displayed in the school cafeteria and T-shirts with the same logo are worn on Spirit Day every Friday. Active PTA involvement, teacher-parent collaboration, and administrative support contribute to the creation of the kind of school community that earned this award. Kindersley is a second home to its students, teachers, administrators, and parents and provides a comfortable place for an inclusive community of learners to develop.

Kindersley elementary serves approximately 600 students from kindergarten to fifth grade. The school population is predominantly Latino, approximately $45 \%$. Anglo students make up the next largest population at about $38 \%$, with Asian, African American, Pacific Islander, Filipino, and American Indian students filling out a rather diverse cultural and socioeconomic population (figures are from the 1992-1993 school year). Previously an almost entirely middleclass, English-speaking school community, $35 \%$ of current students are Limited English Proficient, the majority of whom are Spanish speaking. Kindersley is, therefore, typical of most contemporary urban schools in this country; that is, the population of students has dramatically shifted to reflect the demographic changes in the larger Los Angeles community.

\section{THE CLASSROOM COMMUNITY: THE FIELD OF ACTION}

The classroom selected for this project is one of two bilingual ${ }^{3}$ kindergartens in this elementary school. This classroom was chosen because, as a longtime member of this school community, I had observed that this particular teacher, Janet, centered her curriculum around literacy learning and integrated literacy activities across the curriculum by providing a print-rich environment within which her students are free to explore this new mediun of communication. As we talked over the course of the school year, Janet expressed her belief that children learn through social interaction. As a result, she has created an inviting social space for the children to talk, write, and draw in which the teacher, parent volunteers, and the students create a community of learners where all members actively participate in the learning process. One day, as we were talking about how much the children seemed to enjoy writing together, Janet described her belief that 
usually with young children there is a social aspect to it, you know once they start learning that they're friends and they want to exchange phone numbers, they want to write . . . there's usually a social push to it, you know some way that they can relate to one another.

This orientation to the social processes involved in writing allowed the researcher a focused view of the dynamic social process of learning to write in a classroom where the teacher as expert is "contingently responsive" (Wells \& Chang-Wells, 1992) to the needs of the novice writers. In other words, the teacher has designed her role as a responsive participant to the students' varying social and cognitive needs.

To most of the parents who have had children in her classroom, Janet is the quintessential kindergarten teacher in that she loves children this age and loves to watch "the miracle happen" as they come to her to learn. Students who were in her class as kindergartners regularly stop by her room to say hello or to offer help cleaning up or organizing the room. These young visitors are invariably greeted with loving smiles and a bear hug, followed by an earnest discussion about how things are going in their current classroom. Janet's warm, inviting manner has left its legacy on her students as they continue from grade to grade. One of the first-grade teachers often tells the story of how Janet's former students applaud and cheer whenever her mane or some accomplishment of her students is announced over the loudspeaker.

The first impression upon entering this classroom is that it is full of color and abundant materials. $\Lambda$ new visitor to Janet's room may be taken aback by the seemingly chaotic nature of classroom activity. A closer look reveals, however, a carefully organized physical and social environment in which children's learning is socially mediated and constructed by active participation in activity. The new visitor may also be taken off guard by Janet's open and friendly manner. Stopping by her classroom always means an exuberant introduction to her students with a friendly introduction ritual in which the visitor is asked whether or not he or she is bilingual. The class either celebrates enthusiastically or withers in mock disappointment depending on the answer. Either way, the visitor leaves with a smile.

The room is brightly decorated with children's art and projects displayed prominently around the room. It is full of materials designed by the teacher to provide a print- and number-rich environment in which the children can explore. Janet has decorated the room with multiple graphs, charts, and word boards, such as a birthday-cake string with each child's birthday on it and a tooth string with months of the year marked on each one. As students loose a tooth during the course of the school year, she writes their name on the corresponding tooth. A paper tape with the number of days in school so far tells the students how mliny days they have been in school. Every day that the number zero appears in the day, a special school character, Zero the Hero, comes to visit the class and to talk about the concept of zero. A travel graph that indicates how the children come to 
school (car, bus, or walk) contributes to building a sense of belonging among the students. A language board with the weekly poem and a calendar bulletin board completes the text-rich visual environment.

The room is fairly large and is connected to a neighbor kindergarten classroom by two joint-use rooms: One is a kitchen and supply room and the other is more of a supply storage room. The back door leads to the kindergarten play yard that is separate from the regular school play area. The room itself is divided into play and "work" areas or centers as follows: writing, task, journals, listening, blocks, a library and reading area, and a kitchen play area (see Figure 1). There are two easels set up with paint at all times. The writing, task, and journal centers have cards with the activity title, day of the wcek, and various student names written for each day. These are turned daily so each child can see their task for that day. There is a teacher area in the front of the room where Janet keeps her guitar, stickers, Super Citizen awards, books, record player, and other adult office or teacher supplies. There are no desks, rather, the tables are arranged in such a way that students can talk to one another as they participate in activities. Janet, based on her intuition about the "social push" involved in children's motivation in learning to write mentioned earlier, has arranged the room and structured writing activities in a manner that promotes social interaction between teacher and students and among the students themselves. The focus of this study,

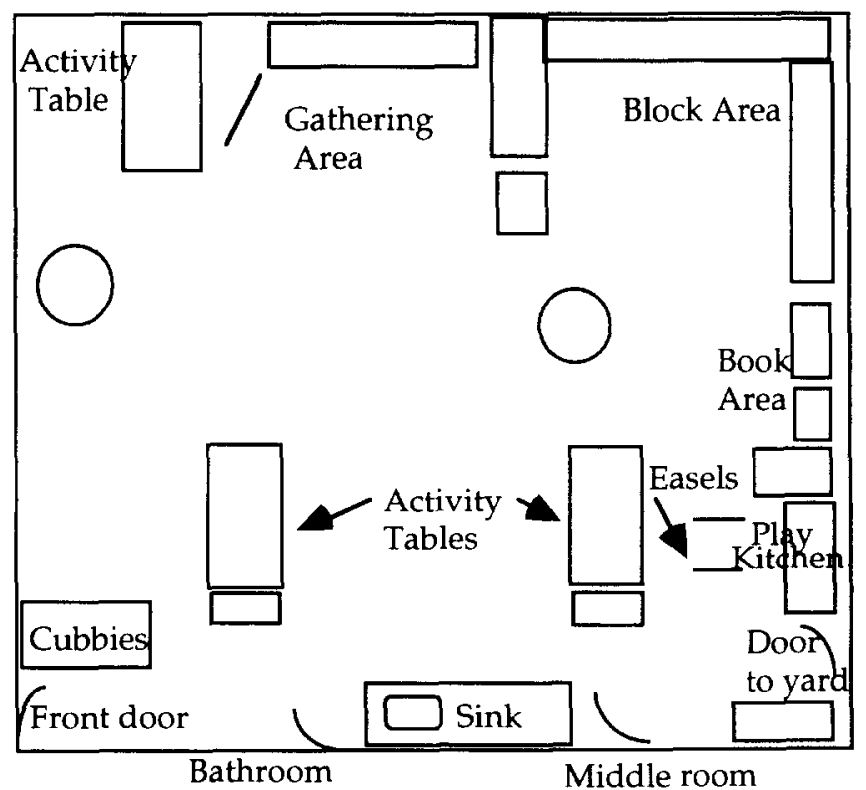

Figure 1. Classroom map. 
the journal writing table, is one such writing activity in which interaction becomes the locus for learning.

\section{LEARNING TO WRITE IN JANET'S CLASSROOM}

Describing the process of learning to write in this classroom is a little like trying to capture the wind. Children write in a flurry of talk, drawing, gesture, and eye gaze that can leave the novice observer spinning with wonder. In this section, I describe the multiple modalities of interaction, such as talk, interaction, body position, and the written word, that laminate the interaction around writing activity through the point of view of the participants in order to expand current definitions of what counts as writing. Microanalysis of transcribed videotape data provides evidence that literacy knowledge is distributed through talk and interaction through shifts in footing (Goffman, 1981), or participant roles, within the participation framework of writing activity.

As mentioned earlier, five participant roles were identified as follows: teacher-scribe, primary author, peripheral respondent, overhearer, and pivot. In the role of teacher-scribe, the teacher is available for each student author as they finish drawing their story and express to her that they are ready for her to write for them. As scribe, she writes their dictated story for them to copy into their journal. The primary author is the student whose dictation the teacher is currently taking. The peripheral respondent role can be filled by one or more students who answer questions posed to the primary author by the teacher from a position outside of the predominantly dyadic interactional space between the teacherscribe and the primary author. Overhearers are those students who are seated at the journal writing table and who listen in on the talk and interaction as each primary author publicly writes his or her story. This is not a passive position; that is, as overhearers, students are keyed into the teacher's talk and actions in such a way that allows them to be prepared to solicit her attention and service as scribe. Furthermore, from this position, students shift to peripheral respondent and primary author. The pivot may emerge from both the peripheral respondent role and from the role of overhearer as knowledge that is placed on the conversational floor is brought into further interactions or into written journal entries. These roles occur sequentially in the participation framework; that is, they are mutually constituted and emerge over time in daily interaction.

\section{Dictated Journal Writing: The Focal Event}

The activity chosen for observation in this study is a journal-writing activity that occurs on a daily basis throughout the school year. The activity itself occurs immediately following the morning literature time during which the teacher or a parent volunteer reads from selected books. After reading and discussing this literature, the students are given their journals and then directed to go to one of two writing tables designated for this purpose. The children begin by illustrating 
the story they wish to tell on the top portion of the journal page, reserving the lined portion at the bottom for the written words.

The teacher has designed her role in this journal-writing activity to serve as scribe for the students' dictated stories. At the beginning of the year, she writes directly on the page just below where the student has drawn the story. The teacher reports that around January things "start getting real exciting" because the students have gained competence in their writing and some have begun to try to write on their own, both in the dictated journal-writing activity and other more loosely structured writing activities that are available throughout the day. She scaffolds this move to independence by writing the student's story on a sentence strip from which the students will then copy into their journal. In her role as scribe, she embeds the teaching of basic literacy skills, such as letter identification and sounds and their connection to spelling.

The teacher's articulated goal of this activity is for the students to become independent writers as defined by the adult model; that is, the students are socialized through writing to write as adults would write. The teacher describes her goals for this activity as being motivated by her desire to provide a supportive environment for the students to develop their language skills. She expressed these goals as follows:

I want this to be a classroom where they feel really accepted and know that no matter how they come up with the word "tugboat" it's gonna be fine with me. So those are my, my basic goal is to get them writing on their own. That's my goal. My other goal is, along side of that is that 1 develop their language through literature and through songs through poetry through our class discussions and I try to get them to be able to verbalize it.

Her goal, then, is to move the students toward independent writing. She defined independent writing as writing "how an adult would write." She saw her role as providing the adult model upon which the children would base their own writing. balanced with a respect for the students own knowledge about writing.

My role is to show the adult model if I need to but my role is to nurture what they already have inside of them. And I think the adult model is very valid. It's a real combination. It's a real balancing act between the adult model of how we write and what's already in them and validating that.

This writing process socializes the students to what the teacher views as the adult writing model and occurs through talk and interaction in the community construction of text in particular ways. In this classroom, text is socially constructed and mediated by language as students shift roles in the participation framework. Specifically, the range of participant roles available to the students determined the nature of the participation framework that evolved. In this way, the participation frameworks emerge as situated language structures that mediatc the writing socialization process in face-to-face interaction over time. 
When discussing the teacher's goal of moving her students toward independence, it is important to remember that this one journal-writing activity does not account for the full range of language activities in this classroom through which the children learn to make meaning with text and come to understand what counts as writing. The goal of this particular activity focuses on developing the student's ability to construct text according to the forms and conventions of standard English. The teacher accomplishes this goal by adjusting her role as scribe over time so that she transfers this responsibility for writing to the student author. About one third of the students in this classroom became more independent writers; that is, the teacher no longer served as scribe for their journal stories. However, she continued to mediate their writing development through language as they coparticipated in sounding out words.

As described earlier, the teacher's role is to serve as scribe for those students who ask. The teacher gives the students a few minutes to get started, then determines who is ready, either by asking directly or by responding to a solicitation. The dictation process begins as the primary author is identified.

\section{Establishing the Primary Dyad}

The primary dyad serves as the starting point of the emerging participant roles in this activity and begins the dictation process. The teacher establishes the primary dyad as she identifies a primary author, or student who is ready to dictate his or her story, and then arranges the environment so as to establish a predominantly dyadic interactional space. The teacher moves to position herself next to the author and closes off the physical space by lowering her body and shifting her body position to face the student. The student's attention is directed to the tools of writing, specifically the journal page itself. The teacher then begins her role as scribe as she writes the story of the primary author on a sentence strip.

As the following excerpt indicates, the teacher begins the dictation process by offering her assistance to the participants as a whole, then, upon identifying who is ready to begin dictation, creates a primary dvad that includes herself and the identified student. Primary dyad is defined here as the dyadic exchange between two interlocutors (see Figure 2).

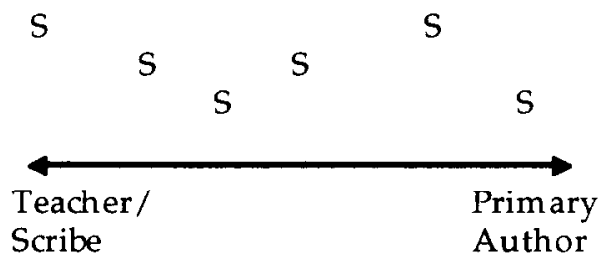

Figure 2. Predominantly dyadic interaction. 


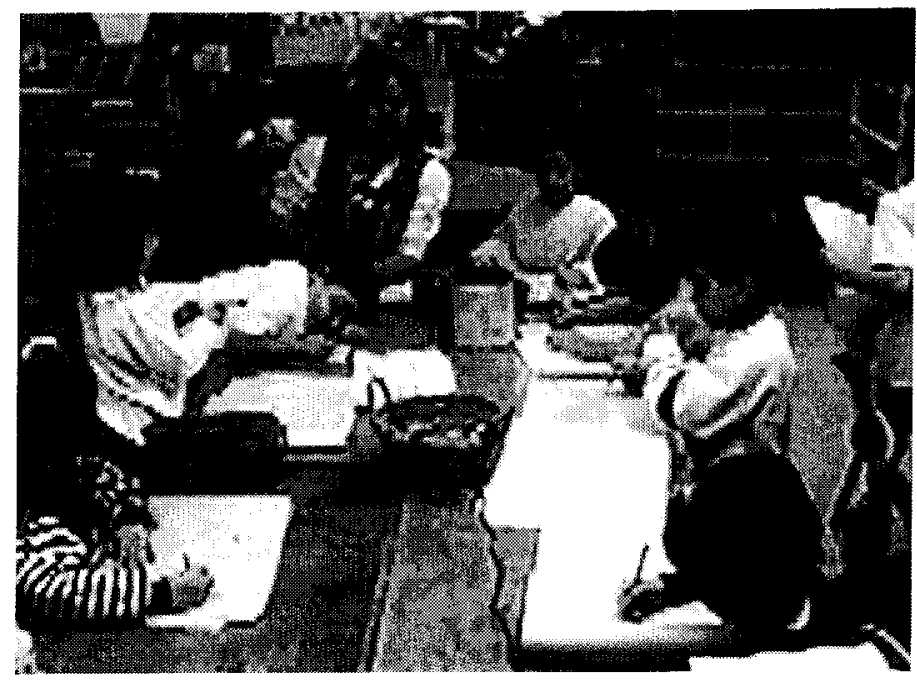

Figure 3. Establishing the primary dyad.

This is not, however, an exclusive dyadic space as the ever-present overhearer is also actively engaged in the writing interaction, whether this attention is displayed or nondisplayed. It is from this peripheral position that students both become primary author and shift to the role of peripheral respondent. In order to make these shifts, however, the student must breach the social space the teacher has created with the primary author. The teacher has established explicit and implicit norms that govern the sanctity of this dyadic interaction. Children are required to rest their hands on her shoulder, for example, if they want to talk to her or show her their work. She will not respond to interruption but will sometimes say "remember my rule" as a reminder of proper entering procedure. In this way, the teacher "disattends" (Goffman, 1974) to competing events in the activity and establishes the boundaries of dyadic interaction. By actively ignoring students who interrupt, she tacitly communicates the inappropriateness of these attempts to enter the dyad and. over time, socializes the students to a normative structure of participation in interaction during this activity. At the same time, this validates the importance of the student with whom she is working and of the writing they are doing together. All of this contributes to the establishment of a primary dyad as described in the following example.

Just prior to this writing period, the teacher read to the class as a whole and then divided the group into two smaller groups. There were eight students arranged around the table during this observation. The teacher circulated around the tahle as she assisted each student in the accomplishment of the day's journal 
entry. In the following excerpt, the teacher identifies the first student, Mary (see Figure 3, left front in photo), who has indicated that she is ready to write.

\title{
Example $1^{4}$ \\ Establishing the Primary Dyad
}

\author{
19 Teacher: [Are you all ready to write your story first $\uparrow$ \\ 20 \\ 21 \\ 22 \\ [((kneels down next to Mary)) \\ you want to tell me your story $\uparrow$ \\ $(0.2)$ \\ 23 okay. \\ 24 Mary: [Bird \\ 25 \\ 26 \\ Teacher: Bird $=$ \\ [((points to bird on paper $))$ \\ $27 \quad[(($ Teacher begins to write on sentence strip $))$
}

After identifying the primary author, Mary, the teacher asks if she is ready to write her story first (Line 19), then kneels down on the floor next to where Mary is sitting and asks again (Lines 20-21). By physically changing her position from the head of the table to the floor next to Mary, the teacher creates a space within which she can interact with the student in such a way as to restrict the other students' access to the interaction. In this way, she establishes the physical boundaries of the primary dyad. These boundaries are reinforced as the teacher circulates the table in a "moveable" space while the students work in a "fixed" space in the activity. Furthermore, this allows the teacher the power of decisions as to who she works with and who enters into interactions with her.

Mary begins her narration by saying the word "bird" and pointing to the picture she has drawn (Lines 24-25). The teacher repeats the word and begins to write the story (Lines 26-27). Hannah, a neighboring student to Mary's left, had established a few minutes earlier that she did not need help writing her story but closely observes interaction in the primary dyad of the teacher and Mary. It is at this point in the activity that Hannah, sitting next to Mary, begins her attempts to enter into the dyadic interaction between the teacher and Mary. The teacher consistently maintains the dyad's boundaries by disattending to Hannah's peripheral insertion attempts, thereby casting Hannah's talk as "out of frame" activity (Goffman, 1974). In this way, Hannah assumes the role of peripheral respondent as she attempts to engage the teacher. Although out of the dyadic frame, Hannah as peripheral respondent remains in the larger classroom writing-activity frame within which peripheral utterances are tolerated.

In this classroom, then, the teacher does not tell the peripheral respondent to be quiet, to work on her own, or to let the primary author figure words out for herself. Rather, the teacher actively tolerates these utterances. This is crucial to the process of socially mediated learning and in the assisted performance of student movement in their zone of proximal development (Rogoff, 1990; Vygotsky, 1962, 1978). This 
tolerance response was commonly used by the teacher as a strategy that assists her in accomplishing her goal of completing the dictation of all the participants. In other words, she could not complete all the students dictated stories if she responded to each comment from the peripheral respondents or other requests for her attention. Additionally, this strategy serves to socialize the students to accepted behavior during writing and to the appropriate times and methods for gaining access to the teacher. As mentioned, the teacher has explicit and implicit rules for gaining the floor and by ignoring the inappropriate attempts, she socializes the students to her preferred methods of entry.

\section{Peripheral Respondent}

The following example illustrates Hannah's attempts to move toward full participation in the primary dyad. Her attempts are tolerated-she is not told to be quiet-but she is not ratified or acknowledged by the teacher as a primary interlocutor, thereby reinforcing the normative practice in the larger classroom framework of calling out responses in this manner. The notion of gaining access to full participation in the primary exchange relates to what Lave and Wenger (1991) referred to as legitimate peripheral participation. Peripherality, as defined here, is a positive position and locates the learner, Hannah, within a social structure into which she is attempting to gain fuller participation as a central speaker and addressee. Changes in location (i.e., more intensive participation) constitute learning trajectories, developing identities, and forms of membership (Lave \& Wenger, 1991). In this view, Hannah, as peripheral respondent, gains peripheral access to the primary dyad and moves toward fuller participation through repeated attempts to enter the interaction (see Figure 4).

In the following excerpt, Hannah initiates an interaction by calling the teacher's name (I ine 39). The teacher does not acknowledge this attempt to enter the interaction and continues to spell the for Mary (Line 41). In Line 42, Hannah reads the word, which again goes unacknowledged. The teacher continues her conversation with Mary and asks her what letter little starts with. The answer is provided by Hannah (Line 45), yet is unratified by the teacher (see Figure 5).

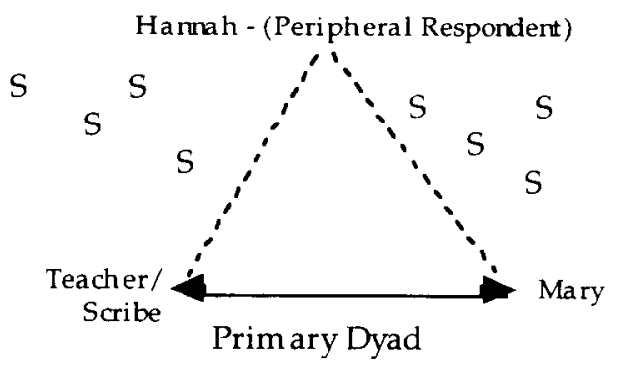

Figure 4. Hannah as peripheral respondent. 


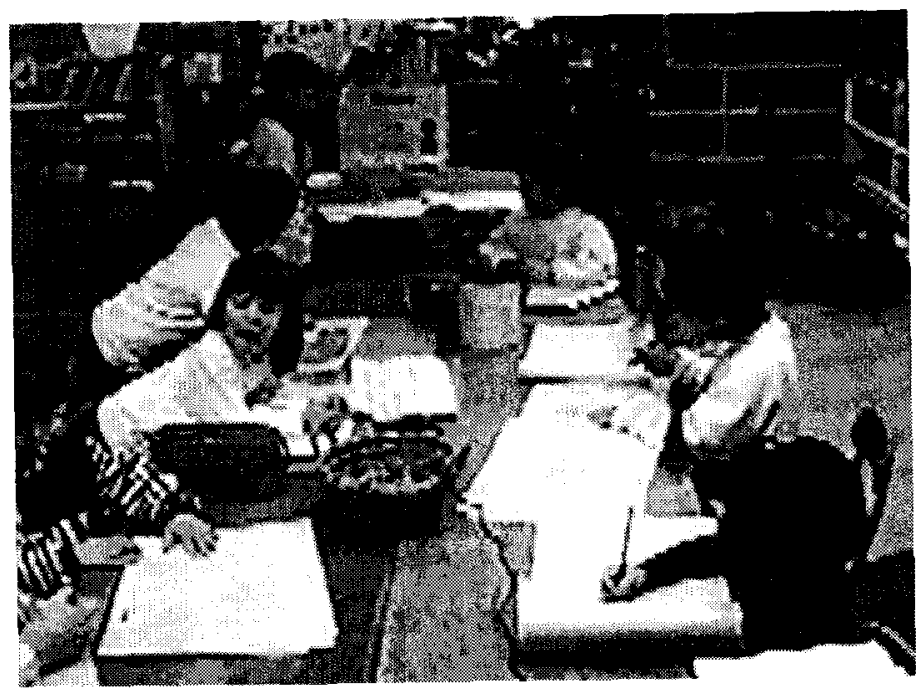

Figure 5. Peripheral respondent.

\section{Example 2 \\ Peripheral Respondent}

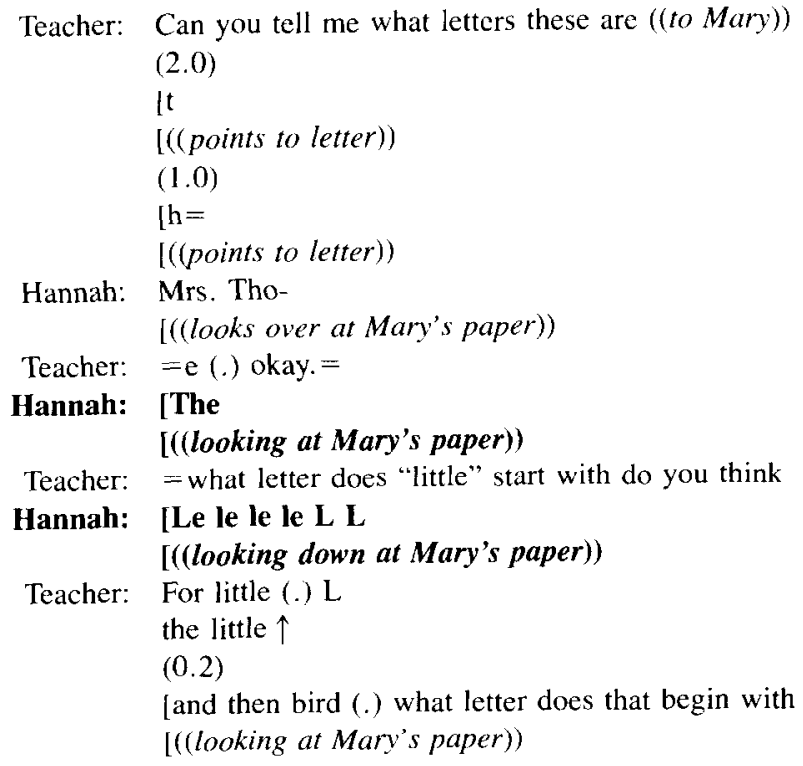

In this example, we can see another occurrence (Lines 37-44) of this teach- 
er's common disattending strategies that allow her to have a focused interaction with individual students in the context of group activity. The teacher neither verbally ratifies Hannah's attempt to gain access to the floor nor responds to Hannah's correct answer to the question posed to Mary: "What letter does little start with do you think?" In this way, while disattending to Hannah's insertion attempts she teaches Mary, Hannah, and other student onlookers the socially appropriate behaviors associated with being a member of this classroom community. Norms and expectations for appropriate participation, then, are highlighted by observing what occurs at points where frames clash (Green \& Weade, 1987). In other words, the teacher's dyadic "teaching frame" excludes Hannah's insertion attempts as out of frame (Goffman, 1974) and, therefore, inappropriate. Hannah remains, however, as a central participant in the larger frame of journalwriting activity.

This excerpt also provides an illustration of one of the ways in which the teacher uses the combination of language and gesture to scaffold Mary's learning. Language, in this interaction, is used to verbally mediate a student's understanding of a common English-language convention, the word the. In lines 34 through 41 , the teacher says each letter of the word slowly and carefully as she points to the written word. Through the joint use of sound and gesture, then, the teacher can indicate to Mary how the word is spelled and which letters match which sound. The leacher has determined which "strategic interactions" (Levine, 1993) are necessary to assist Mary in learning to write this word. Thus, language is seen to serve as scaffolding as the teacher assists the performance of her students.

The teacher spent a good deal of time during writing activity explaining and spelling the to the students. She described it to students as "just one of those words you have to memorize." There was no further explanation of the meaning or purpose of the word, however, and the students often requested its spelling. Her focus on spelling over comprehension and use of the word seems to reflect her interpretation of theoretical understandings from early reading theory that focuses on the memorization of sight words. She does not assist students, even at a basic level, with how to make the connection between letter representation, letter sound, and word meaning. The teacher, by focusing only on the level of memorization, removed higher levels of children's understanding of the that may have been accomplished with a more contextualized discussion of the meaning and purpose of this word.

As the interaction continues, Hannah, from her position of peripheral respondent to the primary dyad of the teacher and Mary, moves into a new primary dyad with a student, John, across the table, thereby cstablishing the position of pivot. It is possible that the role of peripheral respondent is a prerequisite to the development of a pivot because, if Hannah's contributions had been ratified, then the conditions would not exist for her to shift her gaze and talk to another student. In other words, if a triad is created, the role of pivot does not evolve and 
cannot function to circulate knowledge from one interaction to another. Howcver, the requisite nature of the role of peripheral respondent in the emergence of the role of pivot does not exclude other participants from serving as a pivot in the interaction. The position of overhearer, for example, is also situated in the participation framework in such a way that can facilitate the circulation of knowledge from the conversational floor to other interactions. The following section describes the phenomena of the role of pivot and illustrates the dynamics of its position in the data.

\section{Pivot}

Microanalysis of face-to-face interaction has indicated the role of pivot as a key position in the participation framework within which the circulation of knowledge is facilitated and builds on Goffman's (1981) original definition. Goffman's notion of a pivot describes this position as being between two conversations, but keeping each separate. In the model described in this analysis, however, the pivot opens interaction between participants and swings knowledge from the primary dyad to other activity participants, thereby redefining their status from overhearers to interlocutors (see Figure 6). The pivot expands the nature of the participation structure by expanding opportunities for participation and access to knowledge. Without this position, students would have limited access to knowledge that is discussed in dyadic interactions between the teacher and the primary author.

Pivot is, therefore, one position within the participation framework that initiates and facilitates the social distribution of knowledge. In the following interaction, Hannah, after repeated attempts to enter the teacher-Mary dyad, turns her

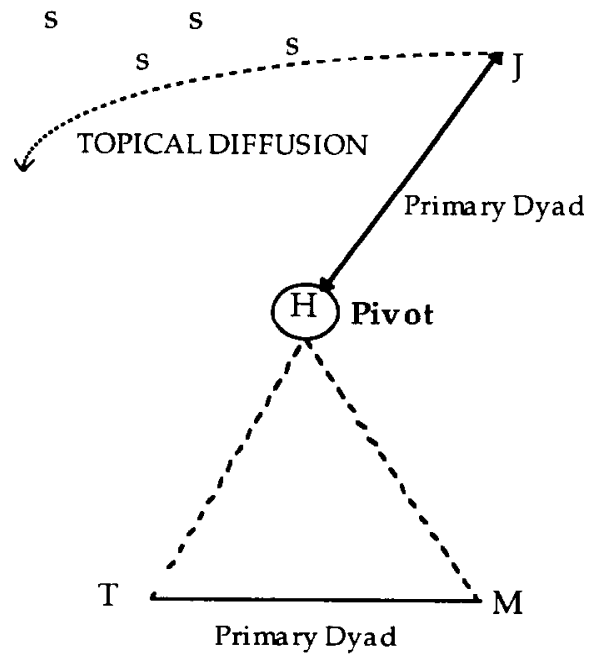

Figure 6. Pivot. 
talk and gaze across the table to John. It is at this moment that the knowledge of letter sounds that was being discussed between the teacher and Mary is made accessible to the other students seated at this table. Given the teacher's strictly monitored rules for entering one-on-one teacher-student interactions, Hannah provides these student overhearers access to knowledge that would have otherwise been less available to them.

\section{Example 3 \\ Pivot}

54 Teacher: And then bird (.) what letter does that begin with

55 Mary: IBe

$56 \quad$ [((looking at the place where the teacher wrote the letter $)\}$

57 Teacher: Be- B

58 Hannah: B-[be-ber- ber- B

$59 \quad[(($ looks across the table to John $))$

60 John: [Bu (.) bu (.) balls]

61 [((stops writing and looks at Hannah $))$

62 Mary: [Wants to]

63 [((points to her paper as she continues her dictation))

64 Hannah: |Ball start with B

65 [((looks back to the teacher and Mary $))$

In this sequence, Hannah (Line 58) takes the letter $b$ from the neighboring dyad (teacher-Mary) and offers it across the table to John (Line 59), who takes

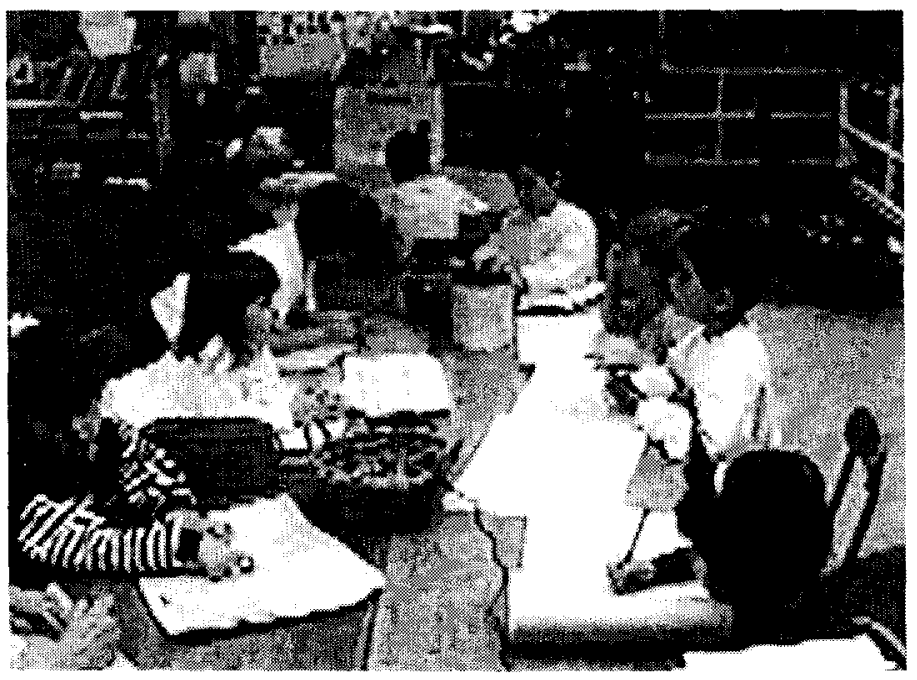

Figure 7. Pivot. 
up her utterance by repeating and then elaborating the letter sound (Line 60). In this conversational move, Hannah establishes the role of pivot as she circulates the appropriated knowledge of the letter $b$ to John. She turns to share her greater understanding, "Ball starts with $b$," with the teacher, but is, once again, unacknowledged. This transformation of the participation framework is a critical shift in the interaction. Hannah does not, as in Goffman's (1981) definition of pivot, create a new topic or maintain a separate conversation with John. She functions in two overlapping frameworks but carries information from one predominantly dyadic interaction to another dyadic structure across the table.

Furthermore, as Hannah, in the role of pivot, enters into dyadic interaction with John (Lines 58-60), she changes his participation status to primary interlocutor and through this change impacts the other student participants. They remain overhearers, so to speak, but topical diffusion occurs in the process. In other words, literacy knowledge that was observed during talk in the primary dyad circulated among the activity participants. Topical diffusion, then, is a consequence of talk and interaction in the activity. The topics of conversation among the primary interlocutors find their way into the drawings of these peripheral overhearers. Each student's story, for example, includes a house and a bird-the same topics that are in Mary's story. The storyline varies in each student's writing but the central setting and characters are the same as Mary's. In this way, there is a nonlinear development of knowledge and skills that is distributed in the activity as overhearers take knowledge from the primary dyad into their own storics.

The notion of diffusion is adapted from theories of language change developed in historical linguistics. This research suggests that changes in speech habits in a single community can be traced historically to a linguistic "parent" (Hockett, 1964). Diffusion is defined as the spread of culture traits from one group to another. The "borrowing" culture may replace traits or integrate a borrowed trait into native complexes (Swadesh, 1964). In this analysis, I have adapted these theoretical notions to account for the active nature of interaction as students appropriate topic ideas (traits) from one "parent" story and incorporate these ideas into their own (native) stories. Furthermore, diffusion can help account for the language change that occurs as activity participants move from predominantly dyadic to more multiparty talk and interaction.

At the close of this segment of the activity, the teacher acknowledges Hannah's continuous attempts to answer those questions posed to Mary. The following section describes the ratification of Hannah and her incorporation into a primary triad that consists of Hannah, Mary, and the teacher.

\section{Primary Triad}

Primary triad is defined here as talk and interaction occurring among three interlocutors. The teacher acknowledges Hannah's attempts to enter the primary dyad, thereby altering the participation structure and establishing new 


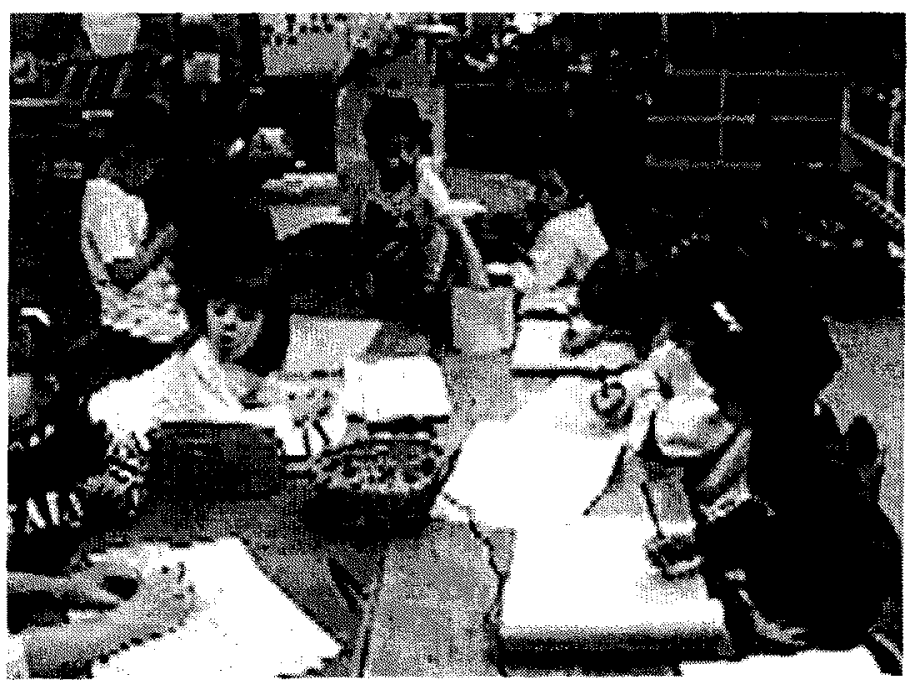

Figure 8. Primary triad.

boundaries for participation in the activity. Any newcomers to this triadic conversation must follow the teacher's entry rules.

Hannah is incorporated as primary interlocutor at the end of the dictation process. The teacher's participation boundaries, then, extend only to the completion of each child's dictation. Hannah has continued to answer questions related to the Mary's text (Line 89) but is not ratified until the final exchange. It is not until the teacher has finished taking Mary's dictation that the space is created for Hannah to be acknowledged for her contribution. In other words, after the "instructional frame" (e.g., "We are doing dictation") is completed, the tcacher's rules for entry relax and other students can talk to her or ask her to help them with their dictation (see Figure 8).

\section{Example 4}

Primary Triad

91

92

93
Hannah: [The: [ho $\uparrow$ use]

l(looking at the teacher's hand as she writess)

Teacher: $\approx$ |house

what letter do you think $h$-h-house begins with

Hannah: Hhhhhh (.) [H

|((looks at teacher $))$

(0.8)

Hannah: $\quad[\mathrm{H}(.) \mathrm{H}$

(r(looks at Mary's paper $)$ ) 
It is not until the last line of this segment (Line 96) that Hannah is ratified by the teacher when she says "thanks Hannah." This statement by the teacher constitutes Hannah's entry into the interaction between the teacher and Mary as the teacher rekeys the interaction from a predominantly dyadic frame to more triadic frame, thereby establishing the primary triad. The teacher and Mary proceed to read back Mary's story and then the teacher shifts back to a dyadic frame to assist another student.

\section{DISCUSSION AND IMPLICATIONS}

This study found that literacy knowledge was circulated and distributed through talk and interaction by shifts in footing within the participation framework of writing activity. The participation framework highlighted the ways in which activity participants gained access to the social distribution of knowledge that would have otherwise been restricted to talk occurring in primarily dyadic interaction. Analysis indicated that the teacher in this study initiated the knowledge distribution process in the creation of a primary dyad. The role of peripheral respondent created the conditions necessary for the pivot to emerge. The pivot, in particular, facilitated knowledge distribution. In this position, the student as pivot took knowledge from one interaction and carried it into the contagious creation of new interactions, thereby expanding access to knowledge which would have otherwise been limited to the primary dyad. Furthermore, these emerging roles indicate the situated nature of participation frameworks as they evolve in context.

In addition, it was found that the teacher was recognized as what could be termed a universal or omnipresent speaker and addressee. In this position as everpresent overhearer, the teacher used the interactional space (Heras, 1993) to instruct all students at the writing table both in terms of content and when addressing behavioral issues. ${ }^{5}$ She understood that the students were listening in on dyadic or triadic interaction and often deliberately used this social space as an opportunity for learning. The students were also aware that the teacher was listening to their interactions as was evidenced by shifts in her attention as she responded to various interruptions from students and other adults present.

Knowledge distribution in this particular activity was found to be a nonlinear spread of literacy knowledge and skills that may or may not have been intended by the teacher. Although Janet designed this activity to promote social interaction, the contagious nature of knowledge distribution in the participation framework may not have been intentional. Research on learning as cognitive apprenticeship looks primarily at the intended ways in which the teacher structures the activity, orients the students to the task, and scaffolds learning through 
varying her degree of participation and assistance. These data indicate that students participate in this learning process in ways that have not, as yet, been discussed in the literature. Through participation in her role as pivot, for example. Hannah contributes to the restructuring of the participation framework and, as a result, expands the nature of participation and membership in the learning community. By relaying appropriated knowledge to the peripheral student participants, Hannah scaffolds learning to write in this activity and stimulates a contagion of learning that is fundamentally and profoundly interactive and social.

This study illustrates the importance of talk in purposeful writing activity and challenges researchers to expand their understanding of the value of talk and interaction in the learning process in general, and the early writing process, in particular. By understanding the ways in which exclusive dyadic interaction with students limits access to literacy knowledge, educators can expand current perceptions of writing curricula to allow for multiparty talk. In this way, the results of this research can help educators determine how various discourses are patterned within and across participation frameworks. which discourse are privileged, by whom, and how these patterns of interaction mediate learning. Research has shown, for example, that literacy learning occurs when students have the kind of access to meaningful participation that flexible participation roles can provide (Gutierrez, Larson, \& Kreuter, in press). This process of learning only occurs through interaction within a participation framework in which boundaries allow for flexible distribution of knowledge.

Furthermore, understanding the implications of talk and interaction in the process of learning to write has particular implications for classrooms with diverse students who enter the new discourse community of school with rich but varied literacy experiences and knowledge. Understanding the interactive social processes of learning will help teachers construct learning environments in which the diversity of children's expertise is not just simply tolerated, but that include the rich cultural experience of all the members of the classroom community in the co-construction of the curriculum and the resulting literacy learning. Teachers are challenged, therefore, to create a community of learners in which social heteroglossia (Bakhtin, 1981), or the inherent multivoiced nature of interaction, is the norm and where voices come together to mediate learning. The implications of this more inclusive, sociocultural view of learning to write are powerful when we consider that most instructional contexts provide little to no opportunity for the kinds of interaction that learning as a socially mediated activity requires (Gutierrez \& Larson, 1994). Furthermore, understanding learning contexts as dynamically multivoiced communities of learners also challenges current liberal humanist pedagogies of tolerance and pushes educators toward a more critical multiculturalism in which the singular voice of the dominant culture is no longer the referent for curriculum development and measures of assessment.

This study contributes to research that emphasizes the valuable role of talk 
and interaction in purposeful activity by providing a deeper understanding of the variety of roles possible in participation. Most classroom research focuses on traditional dyadic interaction between teacher and student in a classic expertnovice model of teaching and learning. This research centers on the dyadic level of interaction to the exclusion of the forms of interaction that occur outside of this focal dyad. The study described in this article furthers research on classroom interaction by expanding the analytic frame to include participants outside of predominantly dyadic interaction as the focus of analysis of the development of writing competence. Furthermore, the nature of the classic expert-novice model of apprenticeship is expanded to include multiple experts in a community of writers. In other words, peripheral respondent utterances can contribute to the community production of text as that text is interactionally negotiated in joint activity.

This research suggests, then, that the crossplay (Goffman, 1981) between students outside of teacher-student dyads and interaction within the primary dyad contributes significantly to the process of learning to write. Specifically, the value of recognizing the consequences of interaction in the primary dyad upon peripheral participant's appropriation of literacy knowledge and, conversely, the consequences of the role of peripheral participants on knowledge construction in the primary dyad are emphasized. Therefore, this study redefines the concept of peripheral participant from the less central role in the participation framework that it is commonly assumed to be by teachers, to a key contributor to the social mediation of the writing process. Teachers have misunderstood and underestimated the ways in which peripheral participants appropriate and distribute literacy knowledge in classrooms. Thus, this research pushes the boundaries of what counts as central participation to include all the participant roles in joint activity.

Consequently, the point of reference for learning to write in classroom interaction moves beyond the notion of a speaker-recipient dyad to a more expansive model that acknowledges all the participants in writing activity as central to the learning context. Learning to write, then, is not accomplished solely by the individual but occurs both through direct and peripheral participation in joint activity. This research illustrates, therefore, how moment-to-moment interaction affects the larger context of literacy instruction by documenting how the teacher and students consciously use the public interactional space as an instructional space within which peripheral participants actively coparticipate in the learning process. In other words, students who have commonly been considered to be working independently are, in fact, learning and assisting others in ways not previously identified. This study suggests, then, the necessary centrality of all the participants in the mediation of writing activity and the crucial role of periphcral participants in the learning process.

Furthermore, this research suggests that in order to fully understand what counts as literate knowledge in classrooms, it is important to look at the broader realm of interaction in language activities. Although researchers have recognized 
that learning to write is an intramental process, the broader arena of intermental social processes and their contribution to learning have not been fully understood in practice. This study challenges, therefore, the efficiency of the traditional dyadic interactional frame as the locus of learning and as the subject of research.

\section{Endnotes}

1. The definition of competency used in this study reflects notions of "communicative competence" (Gumperz, 1981) that link understanding of language to interpretations of context.

2. All names have been changed to maintain the confidentiality of the participants.

3. This study did not focus on the fact that this was a bilingual classroom. It is mentioned in the context of the site description to present a complete picture of the classroom.

4. The following transcription conventions, adapted from Atkinson and Heritage (1984), are used in the examples given.

Colons denote sound stretch ("The:"); brackets indicate overlapping speech.

John: [Bu (.) bu (.) balls]

Mary: [Wants tol

Equal signs indicate closely latched speech, or ideas.

Teacher: $=\mathrm{e}($.) okay $=$

Hannah: The

Teacher: = what letter does "little" start with do you think

Intervals of silence are timed in tenths of seconds and inserted within parentheses; short, untimed silences are marked by a dash when sound is quickly cut off ("Mrs Tho-") or with a period within parentheses (.) as seen in the examples provided. Rising intonation within an utterance is marked with an arrow ("ho $\uparrow$ use"); falling intonation at the end of an utterance is indicated with a period ("okay."); descriptions of speech or gesture are italicized within double parentheses ("( (points to bird on paper $))$ "); single parentheses surround items of doubtful transcription; boldface indicates items of analytic focus.

5. Analysis of the larger data set reveals that all participants in this writing activity were keyed into interaction in the primary dyad. See Larson (1995) for a more elaborated discussion.

\section{REFERENCES}

Anold, P. (1991). Writing development. Philadelphia: Open University Press.

Atkinson, G.M., \& Heritage, J. (1984). Structures of social action: Sudies in conversation analysis. Cambridge, England: Cambridge University Press.

Bakhtin, M.M. (1981). The dialogic imagination (M. Holquist, Ed., and C. Emerson \& M. Holquist. Trans.). Austin: University of Texas Press.

Bereiter, C., \& Scardamalia, V. (1982). From conversation to composition: The role of instruction in a devclopmental process. In R. Glaser (Ed.), Advances in instructional psychology (pp. 164). Hillsdale, NJ: Erlbaum. 
Bloome, D. (1991, June). Interaction and intertextuality in the study of classroom reading and writing events: Microanalysis as a theoretical enterprise. Paper presented at the 2 nd International Conference on Classroom Ethnography, Mexico City, Mexico.

Dudley-Marling, C., \& Searie, D. (1991). When students have time to talk: Creating contexts for learning language. Portsmouth, NH: Heineman.

Duranti, A. (in press). Linguistic unthropology. Cambridge, England: Cambridge University Press.

Dyson, A. (1993a). From prop to mediator: The changing role of written language in children's symbolic repertoires. In B. Spodek \& O. Saracho (Eds.), Language and literacy in early childhood education (pp. 21-41). New York: Teachers College Press.

Dyson, A. (1993b). Social worlds of children learning to write in an urban primary school. New York: Teachers College Press.

Dyson, A.H. (1987). The value of "time off task": Young children's spontaneous talk and deliberate text. Harvard Educational Review, 57, 396-420.

Dyson, A.H. (1989). Multiple worlds of child writers: Friends learning to write. New York: Teachers College Press.

Dyson, A.H. (1992), Whistle for Willie, lost puppies and cartoon dogs: The sociocultural dimensions of young children's composing. Journal of Reading Behavior. 25. 433-462.

Ferreiro, E. (1978). What is written in a written sentence? A developmental answer. Journal of Education, 180(4), 23-39.

Goffman, E. (1974). Frame analysis: An essay on the organization of experience. Boston: Northeastern University Press.

Goffman, E. (1981). Forms of talk. Philadejphia: University of Pennsylvania Press.

Goodwin, M. (1990). He-said-she-said: Talk as social organization among black children. Indianapolis: Indiana University Press.

Goodwin, C., \& Duranti, A. (1991). Rethinking context: An introduction. In A. Duranti \& C. Goodwin (Eds.), Rethinking context: Language as an interactive phenomenon (pp. 1-42). Cambridge, England: Cambridge University Press.

Green, J., \& Weade, R. (1987). In search of meaning: A sociolinguistic perspective on lesson construction and reading. In D. Bloome (Ed.), Literacy and schooling (pp. 3-34). Norwood, NJ: Ablex.

Gumperz, J. (1981). The linguistic base of communicative competence. In D. Tannen (Ed.), Georgetown University roundtable on language and linguistics (pp. 323-334). Washington, DC: Georgetown University Press.

Gundlach, R. (1992). Children as writers: The beginnings of learning to write. In M. Nystrand (Ed.), What writers know (pp. 129-148). Orlando, FL: Academic.

Gutierrez, K., \& Larson. J. (1994). Language borders: Recitation as hegemonic discourse. International Journal of Educational Reform, 3, 22-36.

Gutierrez, K., Larson, J., \& Kreuter, B. (in press). Constructing classrooms as communities of learners. In P. Smagorinsky (Ed.), Culture and literacy: Bridging the gap between community and classroom. Urbana, IL: National Council of Teachers of English.

Heath, S.B. (1983). Ways with words: Language, life, and work in communities and classrooms. Cambridge, England: Cambridge University Press.

Heras, A.I. (1993). The construction of understanding in a sixth-grade bilingual classroom. Linguistics and Elucation, 5, 275-299.

Hockett, C. (1964). Implications of Bloomfield's Algonquian studies. In D. Hymes (Ed.), Language in culture and society (pp. 599-611). New York: Harper \& Row.

Larson, J. (1995). Talk matters: Knowledge distribution among novice writers in kindergarten. Unpublished doctoral dissertation, University of California, Los Angeles.

Lave, J., \& Wenger, E. (1991). Situated learning: Legitimate peripheral participation. Cambridge, England: Cambridge University Press.

Levine, H.G. (1993). Context and scaffolding in developmental studies of mother-child problem- 
solving dyads. In S. Chaiklin \& J. Lave (Eds.), Understanding practice: Perspectives on activity and context (pp. 306-326). Cambridge. Fngland Cambridge I Iniversity Press

Nichols, J., Bauers, A., Pettitt, D.. Redgwill. V.. Seaman, E.. \& Watson. G. (1989). Beginning writing. Philadelphia: Open University Press.

Ochs, E. (1979). Transcription as theory. In E. Ochs \& B. Schieffelin (Eds.). Developmental pragmatics. (pp. 43-72). New York: Academic.

Ochs, E. (1988). Culture and language development: Language socialization and language acquisition in a Samoan village. Cambridge, England: Cambridge University Press.

Ochs, E. (1992). Indexing gender. In A. Duranti \& C. Goodwin (Eds.), Rethinking context: Language as an interactwe phenomenon (pp. 335-358). Cambridge, England: Cambridge University Press.

Ochs, E., \& Schieffelin, B. (1983). Acquiring conversational competence. London: Routledge \& Kegan Paul.

Ochs, E., Taylor. C., Rudolph, D., \& Smith, R. (1992). Storytelling as theory building activity. Discourse Processes. 15, 37-72.

Philips. S. (1983). The imvisible culture. New York: Longman.

Rogoff, B. (1990). Apprenticeship in thinking: Cognitive development in social context. New York: Oxford University Press.

Rogoff, B. (1992. September). Observing sociocultural activity on three planes: Participatory appropriation, guided participation, apprenticeship. Paper presented at the Conference for SocioCultural Research, Madrid, Spain.

Rogoff, B. (1994, April). Developing understanding of the idea of communities of learners. Scribner Award address presented at the annual meeting of the American Educational Research Association, New Orleans, LA.

Schieffelin, B. B., \& Ochs, E. (1986). Language soc ialization across cultures. Cambridge, England: Cambridge Lniversity Press.

Swadesh, M. (1964). Diffusional cumulation and archaic residue as historical explanations. In D. Hymes (Ed.), Language in culture and society (pp. 624--637). New York: Harper \& Row.

Vygotsky, L.S. (1962). Thought and language. Cambridge, MA: MIT Press.

Vygotsky, L.S. (1978). Mind in society: The development of higher psychological processes. Cambridge, MA: Harvard University Press.

Wells, G., \& Chang-Wells, G.L. (1992). Constructing knowledge together: Classrooms as centers of inquiry and literacy. Portsmouth, NH: Heineman. 